\title{
El régimen matrimonial en el Código de Hattusas
}

\author{
FÉlix Alonso y Royano *
}

\section{INTRODUCCIÓN}

En el año 1986 y en el Boletin del llustre Colegio de Abogados de Oviedo, publiqué un pequeño trabajo divulgatorio sobre el "Código de Hattusas»' '. Seis años después vuelvo a retomar este tema, con pretensión ampliatoria. Mis estudios sobre egiptología y derecho de la antiguedad vuelven a poner, en el punto de mira de mi interés, un nuevo comentario sobre la cuestión, fundamentalmente en cuanto se refiere al régimen matrimonial.

Algunos autores ${ }^{2}$ expresan que "la crítica reciente ha demostrado que deben desterrarse las ideas de "código" y "ley"'. Difiriendo de esta opinión, ya expreso en mi tesis doctoral ${ }^{3}$ que, en efecto, "la ley, aún cuando se encontrara escrita, no podía estarlo en códigos, según el concepto decimonónico y moderno que tenemos de ellos". En este sentido coincido, en parte, con Gaudemet ${ }^{4}$, cuando dice: “El punto más delicado es la determinación de la naturaleza exacta de estas dos tablas. A pesar del nombre con que han sido bautizadas, éstas no constituyen un código. No tiene ni la generalidad, ni el carácter legislativo de estos", pero de lo que no parece caber duda -insisto yo- es que se trata de un conjunto de disposiciones jurídicas de indole coercitiva o de soluciones de derecho.

* Abogado. Miembro de la Fondation Egyptologique Reine Elisabeth de Bruxelas. Profesor. Tutor de la UNED en el Centro Asociado Bizkaia.

ALONSO Y ROYANO, F. "Una pequeña aportación a la historia universal del derecho, a través del comentario al "Codigo" de Hattusas", Boletin del Ittre. Colegio de Abogados de Oviedo, n." 24-25, 1986-1987, págs. 59-66

Burgiere, A., alii., Historia de la familia, t. 1. Madrid, 1985, pág. 106. U.N.E.D

Alonso y RoYano, F. Instituciones familiares en el Egipto faraónico. Tesis doctoral inédita

\footnotetext{
Gaudemet, J., Institutions de lAntiquité. Paris, Sirey, 1967, pág. 86
} 
Por otro lado tampoco podemos olvidar que la ausencia sistemática, es moneda común, no solamente en la compilación hitita, sino en sus homónimos de Hamurabi, Lipit Istar o Isin, por citar los mejor estudiados.

Dos cuestiones merecen la pena destacarse en este, a modo de, preámbulo:

a) Que a los hallazgos arqueológicos de estos textos hay que darles una interpretación subjetiva y provisional, a la espera de alguna inesperada novedad, como ya razonablemente apunta Ceram ${ }^{5}$, y que las costumbres hititas, más evolucionadas que otros pueblos sincrónicos, en tiempos de la III dinastía de Ur, de donde sin duda adoptaron la escritura cuneiforme, prestaron su practicidad y realismo social, elementos básicos que influyeron en otros "códigos" contemporáneos, como expresa Riembschneider ${ }^{6}$.

b) Un supuesto anticipo, sobre todos los demás en varios siglos, a pesar de haberse tenido entre muchos expertos del derecho antiguo, al código de Hamurabi o a la legislación sumeria, como modélicos, no sólo por su aparente antigüedad, sino por lo que, de la mano de ésta, reflejaban sus principios legislativos. Creo, en coincidencia con el profesor Montenegro ${ }^{7}$, que el código hitita puede ser, probablemente, anterior a sus citados homónimos de Ur, Esnhunna, Isin y, por supuesto, al de Hammurabi, además de que podría considerársele quizás, más avanzado que éste, en algunos aspectos ${ }^{8}$.

Los fragmentos de las dos tabletas de arcilla que nos han llegado, están grabados en caracteres cuneiformes de lengua hitita, vigorosa, pero carente de tecnicismos jurídicos y de conceptos abstractos, y se llega a la conclusión de no ser un corpus legislativo, sino más bien el entremezclado conjunto de reglas consuetudinarias, disposiciones reales y resoluciones judiciales, y para Gaudemet ${ }^{9}$, esto explicaria que su articulado se expresa tanto en forma condicional, como imperativa, y por ello este autor razona que se trata de una colección jurídica de reglas consuetudinarias, legales o jurisprudenciales, cuyo objeto no es precisamente una promulgación oficial, ya que carecen de la fórmula declarativa que, con carácter imperativo, encabeza los grandes tratatos hititas.

Ceram, C. W., El misterio de los hititas. Barcelona, Destino, 1978, 272 págs.

Riemschneider, M. Die Welt der Hethiter. Stuttgart 1954.

Montenegro Duque, A., El imperio hitita. Bilbao, Moretón, 1967, 256 págs.

Alonso y Royano, F., ibidem, págs. 59-66.

GavDEMET, J., ibidem, págs. 78.95. 
Sin embargo me surjen dudas respecto a esta autorizada opinión, en base a los siguientes puntos no aclarados:

a) Si bien su carácter oficial no está comprobado, cabe pensar en el, dado que, cuando menos dichas reglas fueron emanadas por la autoridad de escribas y sacerdotes, guiados por la intuición y el buen sentido.

b) Es conocido, por los especialistas del derecho de la antigüedad, que alli donde no emanaban reglas de comportamiento o sentencias de la boca del rey o de los dioses, eran sancionadas por él. Las copias o sucesivas redacciones encontradas en el "Código" hitita, como nos hace ver Korosec ${ }^{10}$, nos inclinan a pensar en que su permanente importancia se debía a la aprobación real de tales reglas, como normas generales de conducta ${ }^{11}$.

c) Las frecuentes analogías, fundamentalmente con el código de Hammurabi, explican no sólo las relaciones sociopolíticas y económicas entre hititas y paleobabilonios, sino similares fenómenos en la génesis de ambos corpus legislativos.

Las tabletas hititas fueron descubiertas por el alemán Winckler, en el pequeño poblado de Bogazköy, en la meseta anatólica, en 1907 y publicadas en 1921, después de su fallecimiento ${ }^{12}$, suponiéndose que fueron redactadas en el siglo XVIII a.C., aunque dan la sensación de reproducir un texto más antiguo ${ }^{13}$.

\section{EL RÉGIMEN MATRIMONIAL}

La familia estaba estructurada según el modelo patriarcal europeo, al menos en aspectos tan fundamentales como el asignar al hombre (padre

Se pueden distinguir 4 estadios en las disposiciones juridicas grabadas y que la primera tableta, en su origen, fue anterior a la segunda, ya que ésta parece un complemento de aquéllas, amén de una redacción más cuidada. Sin embargo, a su vez, la primera tableta parece, en retazos, presentar una nueva y reciente redacción (KOROSEC, C., Les fragments du droit hittite. Leyden 1964, págs 47-54. También el mismo autor en "Le probléme de la codification dans le domaine du droit hittite», RIDA, n. IV, 1957, págs. 93-105.

Confirma esta tesis el que alguna fómula alude a su promulgación por orden del rey. como reconoce el propio GAUDEMET, J., en ibidem, págs. 78-95.

2 Falleció en 1913 y Friedrich y Zimmern publicaron. en 1922 una traducción alemana de las tabletas. En este mismo año, el filólogo checo Hrözny hizo una traducción francesa.

13 Gözte remonta la versión primitiva a una época histórica anterior a Telepinu (1525-1500 a.C.) aunque otros autores piensan que la recopilación está hecha en la época de Suppiluliuma (1375-1335 a.C.) [en este sentido Koschaker] o de Mursil II (1334-1306 a.C.) [así opina Hrözny] Sin embargo Friedrich y Zimmern opinan que la redacción no es anterior a la epoca de Attusil III (1275-1250 a.C.). En contra de ellos, pensando que es más antigua, época de Attusil I (1650?? a.C.), Neufeld 
y esposo) la propiedad de los bienes y personas que integraban la casa familiar. De ahí que el matrimonio, era un acto unilateral ${ }^{14}$ donde el hombre tenía en su mano, el cómo, cuándo y dónde, y la mujer era, normalmente, un mero instrumento, si bien es cierto que, con el transcurso del tiempo y la evolución social del Imperio, se produjo una importante preponderancia femenina en algunos aspectos.

El pueblo hitita, al no tener prejuicios de clase o condición social, probablemente por la temprana y sistemática metodología de ir asimilando e intercambiando costumbres con los pueblos dominados, cuyo conjunto fue conformando una población sumamente heterogénea, el matrimonio podía efectuarse entre componentes de muy distinta condición social y racial. Según el "Código" hitita y lo manifestado por Sartiaux ${ }^{15}$ y Gaudemet ${ }^{16}$, el matrimonio podría efectuarse por compra o por rapto. Si bien se admiten, por la generalidad de los autores, formas de matrimonio, en el pueblo hitita, a través del rapto y la compra, parece que la primera, si nos atenemos al contenido del parágrafo $37^{17}$, no fue lo común. Pese a ello Korosec estima que esta forma sería la primera y la auténtica, invocando a su favor el parágrafo 28 , que manifiesta el caso de una hija que, prometida a un hombre, es raptada por otro. Tal proceder obliga a que, el raptor, restituya al prometido aquello que éste entregó a la joven y, además aclara que, los parientes de ésta no tienen por qué participar en la recuperación de semejante devolución.

Neufeld ${ }^{18}$, por el contrario, estima que este rapto, supuesto que no sea un simulacro entre los protagonistas, no prueba la constitución matrimonial, per se, ni el mantenimiento de vínculo alguno. Se trataria, sin duda, de la ruptura de una promesa de matrimonio $y$, como mucho, de una unión de hecho. Favorece esta hipótesis el parágrafo 37 que, contrario a la autorización del rapto de la mujer, expresa que si en la persecución de un raptor hay 2 ó 3 muertos, no ha lugar a la prueba. Y dirigiéndose al raptor concluye: «Tú eres un lobo.»

Téngase en cuenta que los artículos o parágrafos están numerados por editores actuales, del 1 al 100 para la primera tableta y del 101 al 200, para la segunda. Eso sí, la primera tableta trata, en general de derecho civil y la segunda, de derecho penal.

Sartiaux, F., Las civilizaciones de Asia Menor. Barcelona 1931. 213 págs.

Gaudemet, J., ibidem, págs. 78-95.

"NEUfELD, E., The Hittite laws, traslated into English and Hebrew with commentary. Londres 1951, págs. 145-146. inédito). 
Por el contrario, el matrimonio por compra parece haber sido costumbre común entre los hititas y dentro de sus propias instituciones, algunas como veremos, semejantes a las babilónicas ${ }^{19}$.

En cuanto al matrimonio por compra estaba vedado a los esclavos, ya que éstos no tenían la condición de libres, aunque el matrimonio por rapto podía llevarse a cabo por cualquiera, incluidos los esclavos, aunque para tal caso, la mujer, si era libre, adquiría automáticamente la condición del marido por un período de 3 años, recuperando su primitiva condición de mujer libre, con el transcurso de ese tiempo.

Cuando un joven hitita pretendía esposa, entregaba a los padres o parientes de ésta, una kusata ${ }^{20}$ con lo cual se iniciaba el contrato de promesa esponsalicia a través del precio de adquisición al derecho de contracción matrimonial que entre las partes se acordara. Aún cuando se ignora su naturaleza e incluso si la kusata se entregaba a los padres de la mujer, sin duda se trataba de un instituto similar a la "terhatu" babilónica ${ }^{21}$. Y como segunda fase de la promesa esponsalicia, vendría la entrega de la mujer a modo o especie de traditio puellae y cuyo incumplimiento conlleva las sanciones que prevén los parágrafos 29 y 30 del "Código" hitita.

Para el supuesto incumplimiento de la entrega de la mujer, por parte de sus parientes, éstos deben devolver al prometido el doble ${ }^{22}$ de la kusata que hubiera entregado. Para el caso contrario, es decir, que el prometido no contraiga matrimonio, adquiriendo a la mujer, el párrafo 30 contempla la pérdida de lo entregado por él.

Como se podrá observar, hay una gran similitud entre la "terhatu" babilónica y la "kusata" hitita y parece innegable la analogía entre ambas instituciones que harian pensar en influencias semíticas anteriores y, como entre los babilonios, también el "Código" habla de otras liberalidades esponsalicias y dirigidas al matrimonio. Tal es la iwaru o dote que el padre entregaba a la hija como participación sucesoria que quedaba en poder de la mujer y sobre la cual el esposo disponia de un derecho de goce y disfrute constante matrimonio, pasando al fallecimiento de la esposa, a los hijos habidos en el matrimonio. Su figura es semejante a la seriktu babilónica. Otro tanto puede decirse del assu, semejante al nudunnú ba-

Precio o cantidad que se convenia entre las partes.

Alonso y Royano, F., ibidem.

Para Hrözny y el triple para Neufeld. Tal sanción se indica en el parágrafo 29

BitTel, K., Los hititas. Madrid, Aguilar, 1975, págs. 142-145 


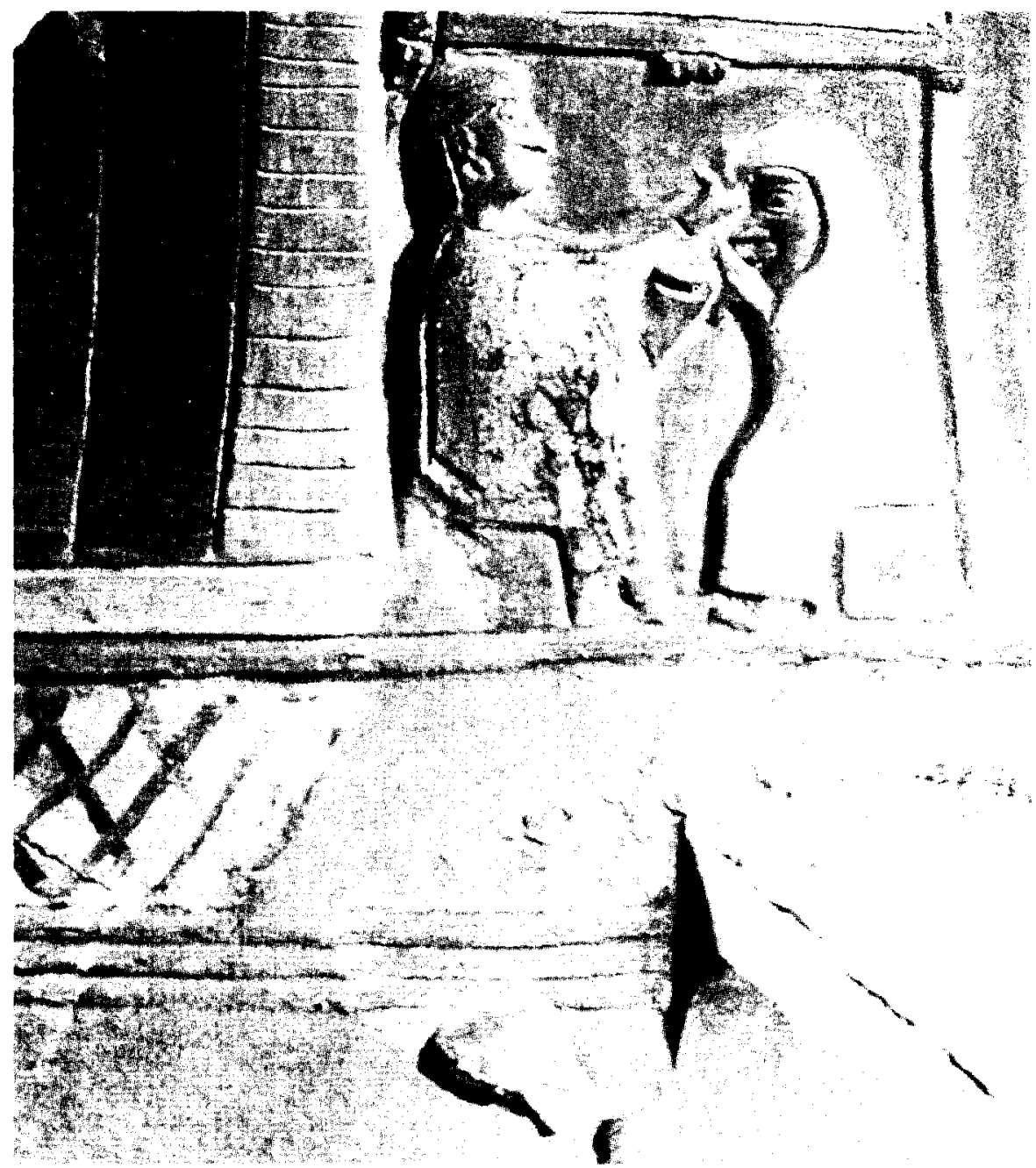

bilónico y que el parágrafo 27 nos descubre, como un regalo que hacia el marido a su mujer.

Asi pues el matrimonio por compra se realizaba con los siguientes requisitos:

1. Acuerdo preliminar entre el pretendiente y el padre de la mujer (en ausencia de éste, su hermano mayor o el resto de hermanos o parientes, por este orden) sobre la "kusata" que debía pagar a la 
familia de la escogida, como un modo de compra disimulada de la mujer, lo cual no es otra cosa que una suerte de contrato de compraventa.

2. Entrega de la kusata y celebración de los esponsales, con lo cual, y por este acto de conjunción de voluntades, entre el pretendiente y el padre de la mujer (la voluntad de ésta no contaba), se convertía en prometida del pretendiente, siendo un compromiso de garantía entre ambas partes, aún cuando entre los esponsales y el matrimonio, podían surgir cuestiones que permitían romper legalmente el compromiso a cualquiera de las partes. Podía, en compensación, renunciar a la kusata. Si la ruptura provenía de los padres de la novia para casaria con un tercero que ofrecía más "kusata», debían devolver al novio la que había entregado.

Como en el de Hamurabi, tampoco en el "Código" hitita se hace alusiones a ceremonias religiosas o fiestas familiares con motivo del matrimonio, pero estamos convencidos de su existencia. Cuando menos ningún documento arqueológico, hasta la fecha, nos impide hacer esta afirmación, sino todo lo contrario. Sólo tenemos que acercarnos al museo de Ankara, en Turquía, para observar un fragmento de vaso (fig. 1) de barro cocido, con relieves polícromos (c. 1600 a.C.) descubierto en Bitik, a unos $25 \mathrm{~km}$ de la capital, y donde figura una pareja sentada de ¿dioses o sacerdotes? Para Bittel ${ }^{23}$ el hombre levanta el velo de la mujer y la ofrece una copa, tratándose de unas bodas místicas. Para nosotros podía perfectamente interpretarse como el ritual de ungir la frente de la mujer con aceites perfumados y previamente sacralizados, por parte del padre o del esposo. Podria tratarse de una boda real conmemorada en la vasija, cuyo resto ha visto el autor. De cualquier modo este fragmento de vaso puede probar la existencia de ritos matrimoniales sacralizados entre los hititas.

El matrimonio era válido inmediatamente de realizada la consumación. Es decir, el paso de "tomar esposa" (esponsales o promesa de matrimonio) era previo a la "posesión plena» (coniuc tio genitalis por la erectio, penetratio y eiaculatio), como concepto canónico, indicativo de nuestra actual idea de "posesión de la mujer por el varón" ${ }^{24}$.

En cuanto a la validez del matrimonio, respecto a los contrayentes, el "Código" se expresa de manera muy incompleta, ya que guardando si-

\footnotetext{
23 Alonso lobo, A. Cabreros de Anta, M. y Alonso moran, S., Comentarios al Código de Derecho Canónico, BAC, 4 tomos (t. 2, título VII «Del Matrimonio»). Madrid 1963, 912 págs

${ }^{24}$ FriedriCH, J., "Einige Umstrittenen Paragraphen", Studia et documenta orientalis ad iura Orientalis Antiqui pertinentia, II, 1939, págs. 8-9.
} 
lencio en lo que se refiere al acto matrimonial en sí, reconoce en su parágrafo 33 , las uniones serviles y las habidas entre libres y esclavos en los parágrafos 31,34 y 35 .

Están prohibidas las relaciones sexuales entre parientes cercanos y se pena con la muerte las de parientes y niños, según el parágrafo 189, también la relación sexual de un hijo con la esposa secundaria de su padre, en vida de éste. Sin embargo es posible el matrimonio entre ambos, si el padre ha muerto, al amparo del parágrafo 190. En el parágrafo 195 se castiga cón la muerte las relaciones sexuales de un hombre con la mujer de su hermano, mientras éste viva, o con la madre, hermana o hija de la esposa (según los apartados b) y $\mathrm{c}$ ) del mismo parágrafo). No obstante, expresa Friedrich ${ }^{25}$, se autorizan estas relaciones (parágrafo 194) entre varias personas unidas por parentesco con una mujer carente de parentesco con ellos. También Korosec ${ }^{26}$ expresó que en el tratado que hace Suppiluliuma con el príncipe del país de Hayasa, contempla la prohibición matrimonial con una hermana o una prima.

Para el caso de viudez de una mujer, el derecho hitita fijaba un orden, semejante al levirato, aunque distinto al de otras legislaciones semitas, sobre quienes debian desposarla: Primero, el hermano del difunto y en su defecto, el padre, el tío o su sobrino.

Con respecto a la vida conyugal, comenzaba con la aportación de los bienes que poseyera el marido y con una dote de la mujer, recibida de su padre como ayuda a los naturales gastos de la casa. El comienzo podía iniciarse en la casa de los padres de ella, con lo que el yerno venía a ocupar sitio en casa de sus suegros, integrándose en dicha familia, o bien la mujer iba a casa del marido. No es peligroso aventurar una tercera opción, aunque no la contemple el "Código": La de "el casado casa quiere" y ocupar una vivienda independiente, aunque parece que esto no fuera frecuente, excepción hecha del desplazamiento del matrimonio a otra ciudad.

Para el supuesto de premuerte de la esposa, la dote instituida pasa al marido, salvo que viva con su suegro. En cuanto a la assu, es devuelta al esposo, en cumplimiento del parágrafo 27 . Si el supuesto de premuerte es del esposo, la mujer tiene derecho a una parte de los bienes de aquél, según contempla el parágrafo 192. pág. 48

KoRosec, C., XI Rencontre assyriologique. Leyden 1962 (se publicó en Leyden en 1964),

Marti-Brugueras, M. M. ibidem. 
La fidelidad conyugal sólo contaba para la mujer, siendo ignorado el adulterio del marido. Aunque los arqueólogos no han descubierto ningún texto referente a la permisión del concubinato legal y por los estudios efectuados, la poligamia estaba prohibia (excepto para el rey, que podía tener esposas secundarias, cuyos hijos podian heredar el trono, en ausencia de hijos procedentes de la reina), el citado concubinato estaba socialmente tolerado.

El parágrafo 197 expresa: "Si un hombre posee a una mujer en la montaña, es falta de aquél y será condenado a muerte. Mas si el hombre la posee en la casa, es falta de la mujer y ella debe morir. Si el marido los sorprende y los mata, no será castigado". Con lo cual se aprecia que los orígenes de nuestra ya caduca figura del uxoricidio que se contemplaba en nuestro código penal, hasta hace 30 años, son muy lejanos en el tiempo y en el espacio. Este derecho de venganza personal que contemplaba la ley había de efectuarse inmediatamente, pues de otra manera el castigo pasaba de ejercitarse personalmente, a ejecutarse por imperio de la ley. La razón de la protección jurídica a la mujer, en el caso de violación, fuera de su casa ("en la montaña», según dice el parágrafo 197, ya comentado), estaba basado precisamente en las dificultades que tenía para impetrar el auxilio de otras personas, contra el violador, y este, al encontrarse solo, y prevalido de su mayor fuerza física, no podía probar la realización del acto carnal con el consentimiento de la ofendida.

\section{EL DIVORCIO}

Como podemos comprobar al hacer este análisis histórico-jurídico, el divorcio en Hatti no sería muy diferente al resto de otras culturas.

A pesar de que algunos autores ${ }^{27}$ aseguran un cierto arraigo matriarcal en la sociedad hitita, que se deja sentir fundamentalmente, en los parágrafos 28,29 y 171 , respecto a la disolución del matrimonio, ésta se producía a través de dos situaciones:

1. La muerte de cualquiera de los cónyuges.

2. El divorcio, fuese por mutuo consentimiento o a petición de alguna de las partes, al encontrarse la otra incursa en causa legal para su otorgación, bien en matrimonios de libre y esclavo o entre cónyuges libres, ya que el parágrafo 31 , sólo contempla el supuesto

Marti-Brugueral, M. A M. Ibidem, pág. 185 
de un hombre libre y una mujer esclava que, tomada por esposa, en tal condición, quedaba libre por el acto del divorcio.

Pero las leyes que nos han llegado no contienen ninguna otra disposición al respecto. Ignoramos, por tanto, las causas de disolución del vínculo por causa de divorcio, aunque es lícito pensar que una de ellas fuese, sin duda, el adulterio de la mujer, dado que si el marido tenía potestad sobre su vida, cuando era sorprendida con otro hombre, mayor razón sería que, si no efectuaba ese derecho de venganza personal, arriba comentado, fuese la ley quien, a través de los tribunales, concediese el divorcio

En cuanto a los bienes existentes en el matrimonio al momento del divorcio, se repartían entre los esposos, sin que se sepa si ese reparto era por mitades o en qué proporción se efectuaba. Sí tenemos noticia de que respecto a los hijos habidos en el matrimonio, excepción de uno de ellos, que se iba con la madre, el resto quedaba en el hogar conyugal con el marido, lo que nos inclina a pensar, al contrario de lo que hacen algunos autores, respecto a supuestos regímenes matriarcales entre los hititas.

También cabe presumir que, en cuanto al domicilio conyugal, para el caso de existencia independiente de éste (ya que lo frecuente, como hemos dicho, es que el matrimonio formado quedara en casa, bien de los padres o los suegros) quien se quedaba con la casa era el esposo con los hijos. Como se apreciará, todo lo contrario de lo que contemplan nuestras actuales legislaciones sobre la materia.

\section{RESUMEN}

El autor es un estudioso de los derechos de la antigüedad anteriores a Roma. Entre otros trabajos se encuentran «Una pequeña aportación a la Historia universal del derecho a través del comentario al Código de Hattusas", "Notas para una Historia general del Arbitraje» (Sobre procedimientos extrajudiciales en el Egipto faraónico), una tesis doctoral sobre las “Instituciones familiares en el Egipto faraónico», «El régimen matrimonial en el derecho paleobabilónico» y «El matrimonio y sus crisis en el derecho de la antigüedad".

En el presente trabajo el autor nos presenta un estudio sobre el matrimonio hitita, los modos matrimoniales, el rapto (restringido) y la compra (lo común), así como su evolución a través de los diversos institutos jurídicos existentes: La kusata, la iwaru o el assu, y la problemática crítica que se podía plantear en el matrimonio y sus soluciones, a la luz del 
conocimiento que nos aportan las tabletas A y B, más conocidas con el nombre de "código" hitita.

Plantea también el autor la posibilidad de ceremonias religiosas y fiestas familiares, apoyándose en las figuras que aparecen en la fotografía, del fragmento de vaso, que aporta del museo de Ankara.

\section{ABSTRACT}

The author is studious of the antique wrights before Rome. Among his different works are "A small study to the Universal History of wrights", through the comment of Hattusas, "Notes for a General History of reference" (about extrajudicial proceedings in the pharaonic Egipt) a doctoral thesis about the "family institutions in the pharaonic Egipt", "The marriage rules in the paleobabilonic wright", and "The marriage and its crissis in the old wright".

At present, the author is working on the hitita marriage, the forms of marriage, the rapture (restricted) and the buying (the usual), so its evolution through different juridical institutions: The kusata, the iwaru or the assu and the problems could be expossed in the marriage and its solutions through the knowledges on tables $A$ and $B$, better known by the name of hitita code.

The author also introduces the possibility of religious ceremonys and family parties, based on the figures showed on photographies of the piece of ceramies from the Ankara Museum. 